\title{
KMT2C Gene Mutation
}

National Cancer Institute

\section{Source}

National Cancer Institute. KMT2C Gene Mutation. NCI Thesaurus. Code C153252.

A change in the nucleotide sequence of the KMT2C gene. 